\title{
Conditioning DRASTIC model to simulate nitrate pollution case study: Hamadan-Bahar plain
}

\author{
Samira Akhavan · Sayed-Farhad Mousavi \\ Jahangir Abedi-Koupai · Karim C. Abbaspour
}

Received: 26 May 2009/Accepted: 4 October 2010/Published online: 20 October 2010

(C) Springer-Verlag 2010

\begin{abstract}
One of the major causes of groundwater pollution in Hamadan-Bahar aquifer in western Iran is a nonpoint source pollution resulting from agricultural activities. Withdrawal of over $88 \%$ of drinking water from groundwater resources, adds urgency to the studies leading to a better management of water supplies in this region. In this study, the DRASTIC model was used to construct groundwater vulnerability maps based on the "intrinsic" (natural conditions) and "specific" (including management) concepts. As DRASTIC has drawbacks to simulate specific contaminants, we conditioned the rates on measured nitrate data and optimized the weights of the specific model to obtain a nitrate vulnerability map for the region. The performance of the conditioned DRASTIC model improved significantly $\left(R^{2}=0.52\right)$ over the intrinsic $\left(R^{2}=0.12\right)$ and specific $\left(R^{2}=0.19\right)$ models in predicting the groundwater nitrate concentration. Our study suggests that a locally conditioned DRASTIC model is an effective tool for predicting the region's vulnerability to nitrate pollution. In addition, comparison of groundwater tables between two periods 30 years apart indicated a drawdown of around $50 \mathrm{~m}$ in the central plain of the Hamadan-Bahar region. Our interpretation of the vulnerability maps for the two periods showed a polluted zone developing in the central valley requiring careful evaluation and monitoring.
\end{abstract}

S. Akhavan - S.-F. Mousavi · J. Abedi-Koupai

Department of Water Engineering,

Isfahan University of Technology,

College of Agriculture, 84156-83111 Isfahan, Iran

K. C. Abbaspour $(\bowtie)$

Eawag, Swiss Federal Institute of Aquatic Science

and Technology, 8600 Dübendorf, Switzerland

e-mail: abbaspour@eawag.ch
Keywords Groundwater vulnerability - SUFI2 . Conditioning · Optimization · Indexing method · Iran

\section{Introduction}

Groundwater is the most important water resource on earth (Villeneuve et al. 1990). This is especially true in arid and semi-arid areas. In most regions of Iran, groundwater is almost the only source of water supply for drinking and agricultural activities. In Hamadan, western Iran (Fig. 1), intensive agriculture, traditional methods of handling sewage, slaughterhouses, and animal farming are principal causes of water pollution on a regional scale. Increasing population has caused agriculture to greatly rely on $\mathrm{N}$-fertilizers to increase crop yield. About $90 \%$ of the croplands are used to grow two main crops of the region: wheat and potato. These lands are located in the vicinity of drinking water wells. In the past 30 years, the water table in Bahar plain (in the vicinity of Hamadan) has dropped by $50 \mathrm{~m}$. This decrease in water table is accompanied by an increase in the application of fertilizers. As reported by previous studies (Rahmani 2003; Jalali 2005; Nadafian 2007), nitrate is the main groundwater pollutant in this region. As drinking water supply comes mainly from groundwater sources, this adds urgency to the study of ways to protect public water supplies of the region.

Groundwater vulnerability mapping is based on the idea that some land areas are more vulnerable to groundwater contamination than others (Gogu and Dassargues 2000). This provides useful information to protect groundwater resources and to evaluate the potential for water quality improvement with changes in agricultural practices and landuse applications (Almasri 2008).

Vulnerability is usually considered as an intrinsic property of a groundwater system that depends on its 


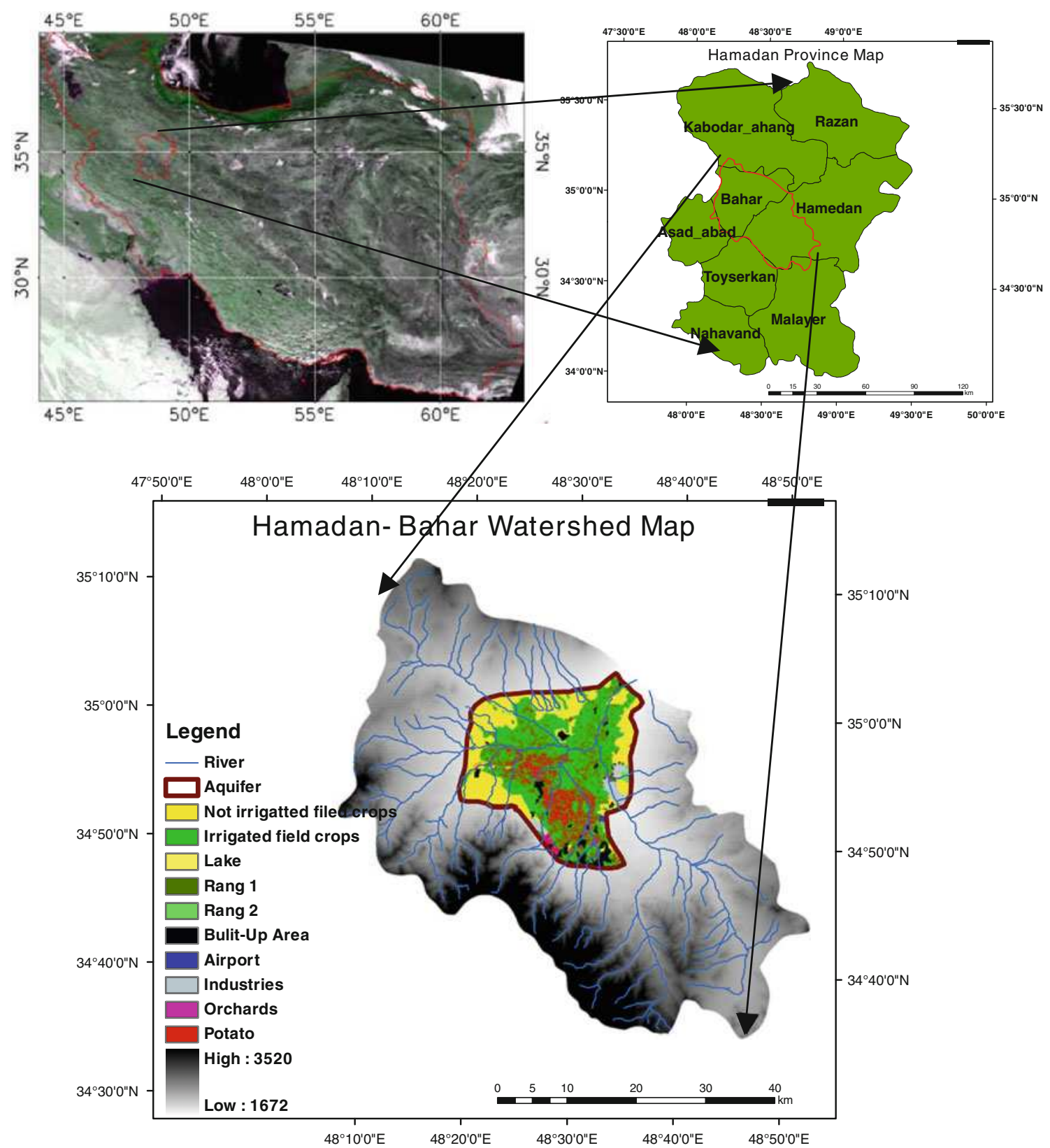

Fig. 1 Study area of Hamadan-Bahar plain in Hamadan province, Iran

sensitivity to natural impacts. Specific or integrated vulnerability, on the other hand, combines intrinsic vulnerability with the risk of the groundwater being exposed to the loading of pollutants from certain man-made sources (Vrba and Zaporozec 1994; Babiker et al. 2005). Groundwater models often have data requirements that cannot be satisfied in many parts of the world (Al-Adamat et al. 2003). The attraction of the vulnerability concept is that it is implemented by classifying a geographical area with regard to its susceptibility to groundwater contamination. Various techniques and methodologies have been developed to evaluate environmental impacts associated with groundwater pollution, and the concept of aquifer vulnerability is one of them.

DRASTIC (Aller et al. 1987) is a model often used to assess groundwater vulnerability to a wide range of potential contaminants (Al-Adamat et al. 2003; Almasri 2008; Rahman 2008). The model uses seven intrinsic parameter of the natural system, which are rated from 1 to 10. Each parameter is then weighted from 1 to 5 . The rates and weights are multiplied for each parameters and added together to produce a so-called "intrinsic" vulnerability index. These parameters include depth to groundwater $(D)$, net recharge potential $(R)$, aquifer media $(A)$, soil media 
$(S)$, topography (T), impact of vadose zone $(I)$, and hydraulic conductivity $(C)$ of the aquifer. Landuse was added to the above system by Secunda et al. (1998) to produce the so-called "specific" vulnerability index. Advantage of the DRASTIC model is that it uses a relatively small number of parameters to compute the vulnerability index, which ensures the best representation of the hydrogeological setting. This makes the model suitable for producing comparable vulnerability maps on a regional scale (Babiker et al. 2005).

Panagopoulos et al. (2006) investigated several studies using the DARSTIC model and reported on some perceived disadvantages such as many variables being factored into one final index (Vrba and Zaporozec 1994; Merchant 1994), qualitative judgment of the selected variables (Garrett et al. 1989), exclusion of many important scientifically defined factors such as sorption capacity, travel time and dilution, and general difficulty of testing the model (Rosen 1994).

Despite these criticisms, many advantages of the DRASTIC model have also been recognized including: the method's low cost of application (Aller et al. 1987), and relative accuracy of model results for extensive regions with a complex geological structure (Kalinski et al. 1994; McLay et al. 2001). In fact, information gained by modeling at different levels of complexities can complement each other and lead to a better understanding of the system under study.

DRASTIC has been applied to many regions around the world, including Tehran-Karaj aquifer, located in central Iran, to classify aquifer vulnerability using fuzzy system (Mohammadi et al. 2008), Kherran plain in Khuzestan (south west of Iran), to construct a groundwater vulnerability map (Chitsazan and Akhtari 2008), Metline-Ras Jebel-Raf Raf aquifer, north east of Tunisia, to classify DRASTIC aquifer vulnerability maps (Hamza et al. 2007), and Kakamigahara Heights, Gifu Prefecture, Central Japan, to estimate aquifer vulnerability and demonstrate the combined use of the DRASTIC and GIS (Babiker et al. 2005).

Few attempts have been made to validate and verify the performance of a DRASTIC model as it is usually applied to areas of no data availability. An exception is the study of Panagopoulos et al. (2006) who modified the rates and optimized the weights of a DRASTIC model based on the correlation of each parameter with measured nitrates concentration in groundwater. But there is an intrinsically high degree of uncertainty in this type of evaluation because pollutant loads are the consequence of complex interactions between environmental, landscape, and anthropogenic factors.

The objectives of this study are to determine the vulnerability of aquifers in Hamadan-Bahar plain with the intrinsic and specific DRASTIC models and to show a simple procedure for training the model on a certain contaminant, in this case nitrate. The training is performed by conditioning the rates and optimizing the weights of the
DRASTIC model on measured nitrate concentrations. ArcGIS (Ver. 9.2) was used to facilitate the analysis and Sequential Uncertainty FItting (SUFI2, Ver. 2) (Abbaspour et al. 2007) was applied for optimization of the weights.

\section{Materials and methods}

\section{Description of the study area}

Hamadan-Bahar aquifer is located in Hamadan province, Iran (Fig. 1). The study area lies between longitudes $48^{\circ} 17^{\prime} \mathrm{E}$ and $48^{\circ} 33^{\prime} \mathrm{E}$ and latitudes $34^{\circ} 49^{\prime} \mathrm{N}$ and $35^{\circ} 02^{\prime} \mathrm{N}$. The total area of Hamadan-Bahar aquifer is $480 \mathrm{~km}^{2}$ and the aquifer is unconfined. Geologically, Hamadan-Bahar aquifer is located on Sanandaj-Sirjan metamorphic zone (Hamadan Regional Water Authority, HRWA). The parent rocks are mainly limestone, calcareous shale and granitic material. The oldest deposits contain slate and schist from Jurassic age that outcrop in the eastern and southern parts of the basin. The Cretaceous deposits consist of the carbonate series. The main portion of the study area is covered by Quaternary sediments and consists mainly of recent alluvium and conglomerate. Hamedan-Bahar alluvial aquifers consist mainly of gravel, sand, silt and clay. The alluvial sediment thickness varies from $25 \mathrm{~m}$ in the sides to $75 \mathrm{~m}$ in the center of the plain. The transmissivity of the Hamadan-Bahar ranges from 100 to $1,750 \mathrm{~m}^{2}$ day $^{-1}$, while the specific yield of the aquifer is about $5-10 \%$. Groundwater supplies approximately $88 \%$ of the water consumed in Hamadan. The region has a cold semi-arid climate with an average annual precipitation of $325 \mathrm{~mm}$ and mean annual temperature of $11^{\circ} \mathrm{C}$.

The main agricultural crops in Hamadan-Bahar plain include wheat and potato. In recent years, large amounts of chemical and animal fertilizers are applied to boost crop production, the consequence of which is large nitrate concentration in groundwater exceeding the standard limits. Table 1 summarizes the annual amount of $\mathrm{N}$-fertilizers applied in Hamadan and Bahar agricultural lands for potato according to the data from the Information Center of

Table 1 Average applied fertilizer for potato in Hamadan and Bahar regions during 2004-2007

\begin{tabular}{|c|c|c|c|c|}
\hline Fertilizer & 2004-2005 & 2005-2006 & 2006-2007 & Mean \\
\hline \multicolumn{5}{|l|}{ Hamadan } \\
\hline Urea $\left(\mathrm{kg} \mathrm{ha}^{-1}\right)$ & 791 & 905 & 301 & 666 \\
\hline $\begin{array}{l}\text { Hen manure } \\
\left(\text { ton } \mathrm{ha}^{-1}\right)\end{array}$ & 28 & 21 & 24 & 24 \\
\hline \multicolumn{5}{|l|}{ Bahar } \\
\hline Urea $\left(\mathrm{kg} \mathrm{ha}^{-1}\right)$ & 390 & 482 & 393 & 422 \\
\hline $\begin{array}{l}\text { Hen manure } \\
\left(\text { ton } \mathrm{ha}^{-1}\right)\end{array}$ & 9 & 15 & 10 & 11 \\
\hline
\end{tabular}


Ministry of Jahade-Agriculture of Hamadan. For wheat, an average of $150 \mathrm{~kg} \mathrm{ha}^{-1}$ urea is applied in these regions.

DRASTIC model and model calibration

DRASTIC is an overlay-and-index method that was developed for the US Environmental Protection Agency by the American Water Well Association (Aller et al. 1987). But it has since became a widely used model around the world. DRASTIC is a conceptual model defined as a composite description of the most important geological and hydrological factors that could potentially affect groundwater pollution. The model yields a numerical index that is derived from ratings and weights assigned to the seven model parameters expressed as follows:

$$
\begin{aligned}
V_{\text {intrinsic }}= & D_{\mathrm{r}} D_{\mathrm{w}}+R_{\mathrm{r}} R_{\mathrm{w}}+A_{\mathrm{r}} A_{\mathrm{W}}+S_{\mathrm{r}} S_{\mathrm{w}} \\
& +T_{\mathrm{r}} T_{\mathrm{w}}+I_{\mathrm{r}} I_{\mathrm{w}}+C_{\mathrm{r}} C_{\mathrm{w}}
\end{aligned}
$$

where $V_{\text {intrinsic }}$ is the intrinsic vulnerability, $D, R, A, S, T, I$, and $C$ are the seven parameters defined in Table 2, and the subscripts $\mathrm{r}$ and $\mathrm{w}$ stand for rate and weight, respectively.

The intrinsic DRASTIC method gives the vulnerability of groundwater against any pollution of surface origin, independent of the landuse or any actual occurrence of pollutants. In a modification, Secunda et al. (1998) added landuse to the model and estimated the specific vulnerability as follows:

$V_{\text {specific }}=V_{\text {intrinsic }}+L_{\mathrm{r}} L_{\mathrm{w}}$ where $V_{\text {specific }}$ is the specific vulnerability, and $L_{\mathrm{r}}$ and $L_{\mathrm{w}}$ are landuse rate and weight, respectively.

The recharge rates and weights used here were based on those proposed by Piscopo (2001) and the landuse rates and weights were based on those published by Secunda et al. (1998). The remaining parameter weights and rates were based on those suggested by Aller et al. (1987). The DRASTIC parameters were manipulated as raster maps in an ArcGIS environment (Ver. 9.2).

For the purposes of this research, the intrinsic and specific vulnerability indices were conditioned on observed nitrate concentrations of the aquifers in the region of study. To do this, both rates and weights were redefined. For new rates of categorical variables, first the average nitrate concentration was calculated for each category and then used in the following equation:

$r(v)_{j}=\frac{\left[\mathrm{NO}_{3}^{-}\right]_{\mathrm{avg}, j}}{\left[\mathrm{NO}_{3}^{-}\right]_{\mathrm{avg}}} \times 10 \times\left\{\underset{j=1, J}{\mathrm{MAX}}\left[\frac{\left[\mathrm{NO}_{3}^{-}\right]_{\mathrm{avg}, j}}{\left[\mathrm{NO}_{3}{ }^{-}\right]_{\mathrm{avg}}}\right]\right\}^{-1}$

where $r(v)_{j}$ is modified rate for the $j$ th category $(j=1, \ldots, J)$, $\left[\mathrm{NO}_{3}{ }^{-}\right]_{\mathrm{avg}, j}$ is the average of nitrate concentration for the $j$ th category, $\left[\mathrm{NO}_{3}{ }^{-}\right]_{\mathrm{avg}}$ is the average nitrate concentration over all categories $\left(\mathrm{mg} \mathrm{l}^{-1}\right)$, and MAX is the maximum of $\frac{\left[\mathrm{NO}_{3}{ }^{-}\right]_{\text {avg. } j}}{\left[\mathrm{NO}_{3}{ }^{-}\right]_{\text {avg }}}$ ratio for all $j \in J$. The multiplier 10 , simply scales $r(v)_{j}$ to a maximum value of 10 . For nominal variables such as depth and hydraulic conductivity, they were first

Table 2 Description and original weights of the intrinsic and specific model parameters. Also given are the weights of the calibrated model,

\begin{tabular}{|c|c|c|c|}
\hline The DRASTIC model parameters & Parameter description & Original weight & Modified weight \\
\hline Depth to water $(D)$ & $\begin{array}{l}\text { Represents the depth from the ground surface to the water } \\
\text { table. Deeper water table levels imply lesser contamination } \\
\text { chances }\end{array}$ & 5 & $0.98(-0.23,1.25)$ \\
\hline Net recharge $(R)$ & $\begin{array}{l}\text { Represents the amount of water that penetrates the ground } \\
\text { surface and reaches the water table. Recharge water } \\
\text { represents the mean for transporting pollutants }\end{array}$ & 4 & $0.79(0.04,1.35)$ \\
\hline Aquifer media $(A)$ & $\begin{array}{l}\text { Refers to the material property of the saturated zone, which } \\
\text { controls the pollutant attenuation processes }\end{array}$ & 3 & $-0.16(-0.74,1.08)$ \\
\hline Soil media $(S)$ & $\begin{array}{l}\text { Represents the uppermost weathered portion of the unsaturated } \\
\text { zone and controls the amount of recharge that can infiltrate } \\
\text { downward }\end{array}$ & 2 & $2.76(0.96,2.87)$ \\
\hline Topography $(T)$ & $\begin{array}{l}\text { Refers to the slope of the land surface. It indicates the potential } \\
\text { for runoff as opposed to infiltration }\end{array}$ & 1 & - \\
\hline Impact of vadose zone $(I)$ & $\begin{array}{l}\text { Defines the material in the unsaturated zone. It controls the } \\
\text { passage and attenuation of the contaminant to the saturated } \\
\text { zone }\end{array}$ & 5 & $2.04(0.84,2.54)$ \\
\hline Hydraulic conductivity $(C)$ & Indicates the ability of the aquifer to transmit water & 3 & $-0.15(-0.25,1.25)$ \\
\hline Landuse $(L)$ & Represents the effect of landuse activity on the aquifer & 5 & $1.23(0.92,2.77)$ \\
\hline
\end{tabular}
including the uncertainty ranges 
classified into several categories (based on Aller et al. 1987) and then the above equation was applied.

After rescaling the rates, the weights were optimized using the SUFI2 (Abbaspour et al. 2007) program of Soil Water Assessment Tool (SWAT)-CUP (Abbaspour 2007). SWAT-CUP was redesigned to run for DRASTIC. This program uses several methods to optimize a given objective function and it is available for use by other DRASTIC users upon request. SUFI2 performs model uncertainty and parameter sensitivity analysis as well as optimization. The objective function for optimization was defined as:

OF $=\sum_{i=1}^{n}\left(V-\left[\mathrm{NO}_{3}{ }^{-}\right]\right)^{2}$

where $O F$ is the objective function, $V$ is the vulnerability value (intrinsic or specific) $\left(\mathrm{mg} \mathrm{l}^{-1}\right),\left[\mathrm{NO}_{3}{ }^{-}\right]$is the measured nitrate concentration in groundwater $\left(\mathrm{mg} \mathrm{l}^{-1}\right)$, and $n$ is the number of measured data. In SUFI2, weights were initially assigned a range of $(0,2)$. These ranges were then modified by the program by performing 500 simulations using Latin-hypercube sampling (McKay et al. 1979). Upon completion of the simulations, new parameter ranges were calculated (Abbaspour et al. 2007) and the process was repeated until no further improvement could be made to the objective function. As SUFI2 is a stochastic program, the final result is shown as $95 \%$ prediction uncertainty (95PPU). The goodness of calibration/uncertainty analysis is quantified by two parameters: $P$-factor and $R$-factor. $P$-factor quantifies the percentage of measured data bracketed by the 95PPU and has a maximum value of 1. $R$-factor quantifies the thickness of the 95PPU band with an ideal value approaching zero. The SUFI2 procedure tries to bracket most of the data within a narrow uncertainty band.

After each iteration, parameter sensitivities were determined by calculating the following multiple regression system, which regressed the Latin-hypercube-generated parameters against the objective function values:

$g=\alpha+\sum_{i=1}^{m} \beta_{i} b_{i}$

where $\alpha$ is the intercept, $\beta_{i}$ is slope of the parameter $b_{i}$, and $m$ is the number of parameters. A $t$ test was then used to identify the relative significance of each parameter.

\section{Model parameterization}

A short description of DRSATIC parameters is provided in Table 2. The basic database used to develop the model is as follows:

1. Depth to water table was obtained using data from 28 piezometers provided by HRWA. The water table levels were subtracted from the elevation of the piezometer wells and averaged over a 6-year period (2001-2006). The depth to water table was then classified into ranges as defined by the DRASTIC model and assigned rates ranging from 1 (minimum impact on vulnerability) to 10 (maximum impact on vulnerability). The deeper the groundwater table, the smaller the rate. The water table layer was converted to raster format with 100-m cell size (Fig. 2a).

2. The net recharge layer was constructed using Piscopo method (Piscopo 2001):

$$
\begin{aligned}
\text { Recharge Index }= & \text { Slope Index }+ \text { Rainfall Index } \\
& + \text { Soil permeability Index. }
\end{aligned}
$$

First, a regional digital elevation model (DEM), provided by the National Cartographic Center of Iran, was generated with a spatial resolution of $20 \mathrm{~m}$. After deriving the slopes, the slope was reclassified according to the criteria given in Table 3. Rainfall, permeability, and the resulting recharge indices were also calculated as specified in Table 3 . Figure $2 b$ shows the recharge map of the region.

3. Aquifer media information was obtained from the bore logs obtained from HRWA and the depth to water table. The raster map is shown in Fig. 2c. Aquifer media layer shows that most parts of the study area have the rating value equal to six (sand with silt and clay).

4. Soil map of the study area $(1: 50,000)$ was obtained from Hamadan Agricultural and Natural Resources Research Center. The soil classes of the study area were arranged based on the classes proposed by the DRASTIC method. As illustrated in Fig. 2d, most parts of the study area have rating value equal to four (silty loam).

5. The slope was calculated as stated in (2) above and classified based on Aller et al. (1987). This variable was removed from the calibration analysis as it was quite uniform for most of the region (Fig. 2e).

6. Impact of vadose zone layer (Fig. 2f) was constructed from the lithological cross-sections obtained from the geophysical data, bore logs and depth to water table data provided by HRWA.

7. To obtain the aquifer hydraulic conductivity map, transmissivity map was constructed using pumping test results provided by HRWA. The transmissivity values were converted to hydraulic conductivity using the aquifer thickness map obtained from HRWA. Figure $2 \mathrm{~g}$ shows that most parts of the study area have hydraulic conductivity values ranging from 4 to $12 \mathrm{~m} \mathrm{day}^{-1}$. 
a

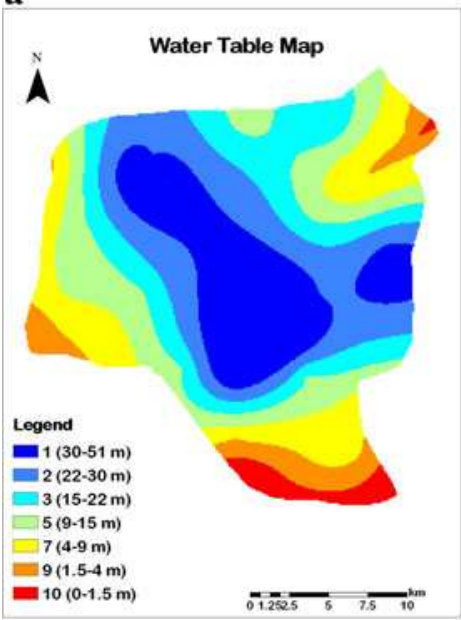

d

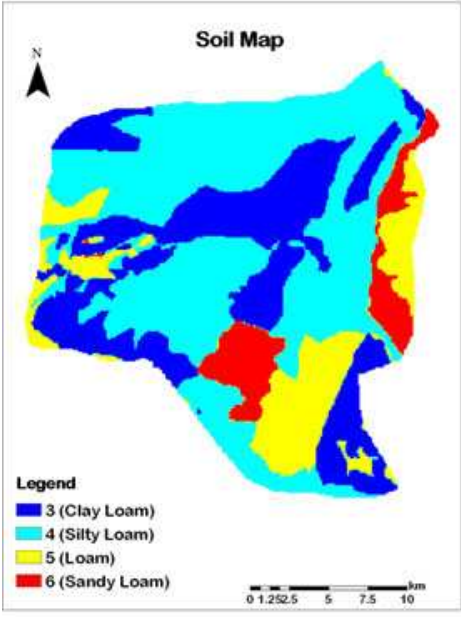

g

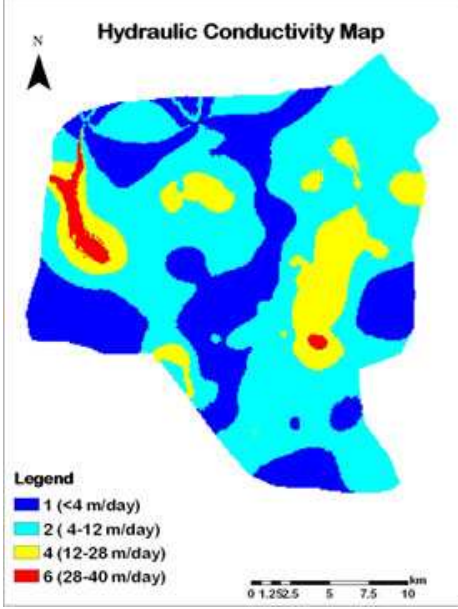

b

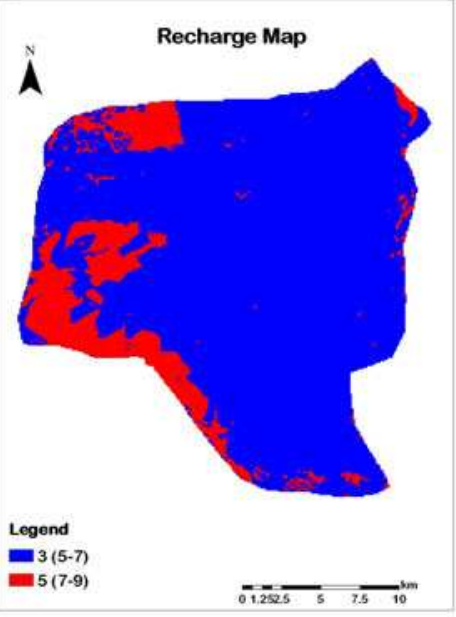

e

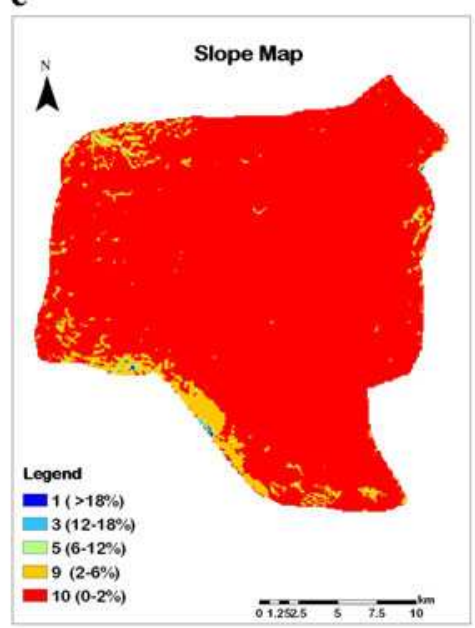

h

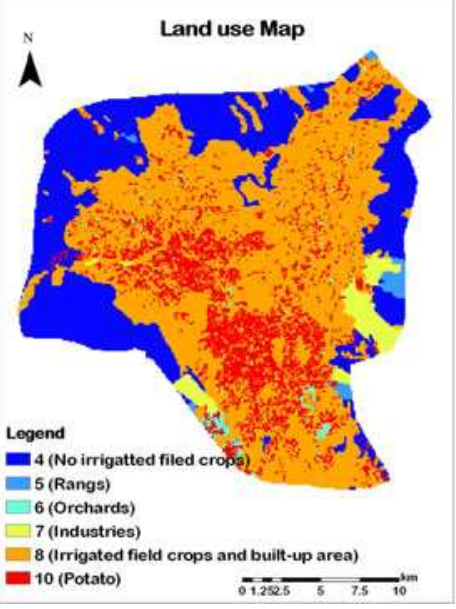

c

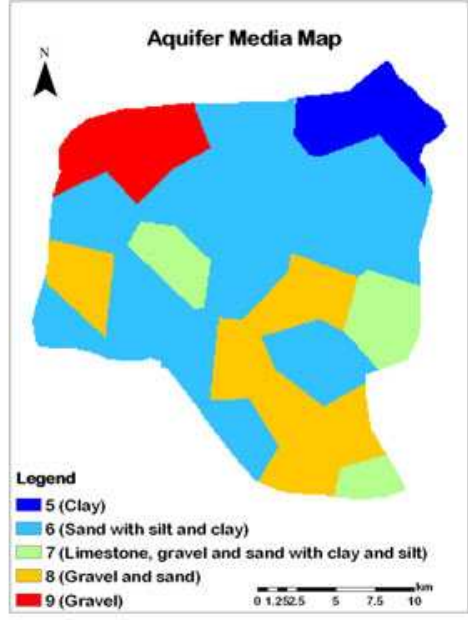

f

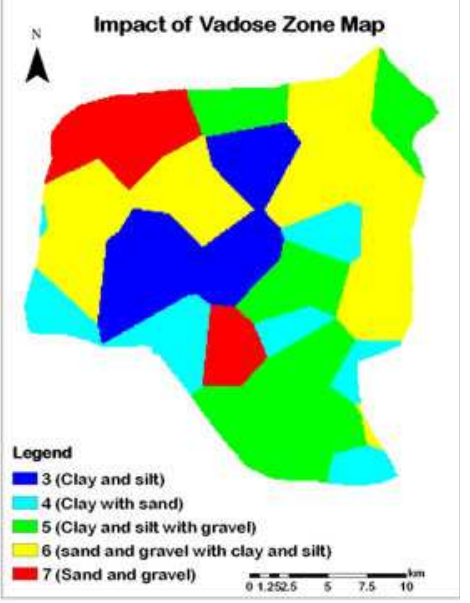

Fig. 2 Maps of DRASTIC parameter rates calculated for the Hamadan-Bahar plain

8. The data for the landuse map were prepared by classifying a LANDSAT-ETM ${ }^{+}$satellite image taken on the year 2000 (http: Ilwww.landsat.org). For this study, ten categories of interest were classified using supervised maximum likelihood classification method with ENVI (2000) (Fig. 1). The reclassification of 
Table 3 Description of slope, rainfall, and soil permeability indices used in the calculation of the recharge rates based on Piscopo (2001) method

\begin{tabular}{|c|c|c|c|c|c|c|c|}
\hline \multicolumn{2}{|l|}{ Slope } & \multicolumn{2}{|l|}{ Rainfall } & \multicolumn{2}{|l|}{ Soil permeability } & \multicolumn{2}{|c|}{ Recharge value } \\
\hline Slope $(\%)$ & Index & Rainfall (mm year ${ }^{-1}$ ) & Index & Range & Index & Range & Index \\
\hline$<2$ & 4 & $>850$ & 4 & High & 5 & $11-13$ & 10 \\
\hline $2-10$ & 3 & $700-850$ & 3 & Moderate to high & 4 & $9-11$ & 8 \\
\hline $10-33$ & 2 & $500-700$ & 2 & Moderate & 3 & $7-9$ & 5 \\
\hline \multirow[t]{2}{*}{$>33$} & 1 & $<500$ & 1 & Low & 2 & $5-7$ & 3 \\
\hline & & & & Very low & 1 & $3-5$ & 1 \\
\hline
\end{tabular}

Table 4 Original and modified rates of the specific vulnerability parameters

\begin{tabular}{|c|c|c|c|c|c|c|c|}
\hline \multicolumn{4}{|c|}{ Depth to water $(D)$} & \multicolumn{4}{|l|}{ Aquifer media $(A)$} \\
\hline $\begin{array}{l}\text { Range } \\
(\mathrm{m})\end{array}$ & $\begin{array}{l}\text { Original } \\
\text { rating }\end{array}$ & $\begin{array}{l}\text { Mean } \mathrm{NO}_{3}^{-} \\
(\mathrm{mg} / \mathrm{l})\end{array}$ & $\begin{array}{l}\text { Conditioned } \\
\text { rating }\end{array}$ & Aquifer type & $\begin{array}{l}\text { Original } \\
\text { rating }\end{array}$ & $\begin{array}{l}\text { Mean } \mathrm{NO}_{3}{ }^{-} \\
(\mathrm{mg} / \mathrm{l})\end{array}$ & $\begin{array}{l}\text { Conditioned } \\
\text { rating }\end{array}$ \\
\hline $0-1.5$ & 10 & 59.17 & 9 & Clay & 5 & 26.47 & 5 \\
\hline $1.5-4$ & 9 & 60.11 & 9 & Sand with silt and clay & 6 & 42.41 & 7 \\
\hline $4-9$ & 7 & 64.37 & 10 & Limestone, gravel, sand with clay & 7 & 35.035 & 6 \\
\hline $9-15$ & 5 & 55.52 & 9 & Gravel and sand & 8 & 58.25 & 10 \\
\hline $15-23$ & 3 & 27.23 & 4 & Gravel & 9 & 33.71 & 6 \\
\hline $23-30$ & 2 & 37.14 & 6 & \multirow{2}{*}{ Gravel } & & & \\
\hline $30-50$ & 1 & 37.88 & 6 & & & & \\
\hline \multicolumn{4}{|c|}{ Soil media $(S)$} & \multicolumn{4}{|l|}{ Impact of vadose zone $(I)$} \\
\hline Soil type & $\begin{array}{l}\text { Original } \\
\text { rating }\end{array}$ & $\begin{array}{l}\text { Mean } \mathrm{NO}_{3}{ }^{-} \\
(\mathrm{mg} / \mathrm{l})\end{array}$ & $\begin{array}{l}\text { Conditioned } \\
\text { rating }\end{array}$ & Impact of vadose zone type & $\begin{array}{l}\text { Original } \\
\text { rating }\end{array}$ & $\begin{array}{l}\text { Mean } \mathrm{NO}_{3}^{-} \\
(\mathrm{mg} / \mathrm{l})\end{array}$ & $\begin{array}{l}\text { Conditioned } \\
\text { rating }\end{array}$ \\
\hline Clay loam & 3 & 27.37 & 4 & Clay and silt & 3 & 41.35 & 6 \\
\hline Silty loam & 4 & 40.12 & 5 & Clay and sand & 4 & 40.33 & 6 \\
\hline Loam & 5 & 76.79 & 10 & Clay, silt, with gravel & 5 & 64.10 & 10 \\
\hline \multirow[t]{2}{*}{ Sandy loam } & 6 & 54.42 & 7 & Sand, gravel with clay and silt & 6 & 52.02 & 8 \\
\hline & & & & Sand and gravel & 7 & 24.26 & 4 \\
\hline Hydraulic ce & conductivity o & f the aquifer $(C)$ & & Landuse $(L)$ & & & \\
\hline $\begin{array}{l}\text { Range } \\
\text { (m/day) }\end{array}$ & $\begin{array}{l}\text { Original } \\
\text { rating }\end{array}$ & $\begin{array}{l}\text { Mean } \mathrm{NO}_{3}{ }^{-} \\
(\mathrm{mg} / \mathrm{l})\end{array}$ & $\begin{array}{l}\text { Conditioned } \\
\text { rating }\end{array}$ & Land use class & $\begin{array}{l}\text { Original } \\
\text { rating }\end{array}$ & $\begin{array}{l}\text { Mean } \mathrm{NO}_{3}^{-} \\
(\mathrm{mg} / \mathrm{l})\end{array}$ & $\begin{array}{l}\text { Conditioned } \\
\text { rating }\end{array}$ \\
\hline$<4$ & 1 & 39.77 & 8 & Non-irrigated field crops & 4 & 37.2 & 5 \\
\hline $4-12$ & 2 & 50.74 & 10 & Ranges & 5 & - & 5 \\
\hline $12-28$ & 4 & 31.25 & 6 & Orchards & 6 & 61.4 & 8 \\
\hline $28-40$ & 6 & - & 6 & Industries & 7 & 25.01 & 3 \\
\hline & & & & Irrigated field crops & 8 & 44.91 & 6 \\
\hline & & & & Built-up areas & 8 & 41.06 & 6 \\
\hline & & & & Potato & 10 & 73.52 & 10 \\
\hline
\end{tabular}

landuse for DRASTIC, however, resulted in six classes based on the procedure of Secunda et al. (1998) (Fig. 2h). For example, in this procedure "irrigated field crops" and "buildup area" fall in the same class.
Finally, groundwater samples were collected monthly in 37 wells across the region of study during fall 2007 to fall 2008. The monthly variations of nitrate concentration were quite small for the sampling period. Almost all ranges of 
DRASTIC parameters were covered by the sampling points. Plastic bottles were filled with the groundwater sample and the samples were analyzed for $\mathrm{NO}_{3}{ }^{-}$by using a DR/4000 Hach spectrophotometer. An independent nitrate dataset containing measurements from a different set of 15 wells was obtained from Rahmani (2003) and used for validation.

\section{Results and discussion}

In the first phase of the analysis, the DRASTIC intrinsic and specific vulnerability indices were calculated. Table 4 shows the rates for all parameters. The weights are reported in Table 2. An interesting observation with DRASTIC's specification of rates is the case of aquifer hydraulic conductivity. It is seen in Table 4 that as conductivity increases, rates also increase. Whereas one would expect that as conductivity increases, the potential for local contamination

Table 5 Intrinsic (specific) vulnerability classes and the areas of groundwater pollution in Hamadan-Bahar plain

\begin{tabular}{llcc}
\hline DRASTIC index & Vulnerability range & Area $\left(\mathrm{km}^{2}\right)$ & Area $(\%)$ \\
\hline Negligible & $69-86(94-119)^{\mathrm{a}}$ & $77(33)$ & $16(7)$ \\
Low & $86-103(119-132)$ & $187(181)$ & $38(37)$ \\
Moderate & $103-119(132-145)$ & $132(175)$ & $27(36)$ \\
High & $119-135(145-160)$ & $85(88)$ & $17(18)$ \\
Extreme & $135-152(160-192)$ & $5(9)$ & $1(2)$ \\
\hline
\end{tabular}

${ }^{a}$ Numbers in brackets are based on specific vulnerability model should decrease due to a faster moving groundwater and increased dilution.

As it is usually done (Mohammadi et al. 2008), the intrinsic vulnerability scores of $69-152$ obtained for the region were divided into five classes (Table 5). The resulting vulnerability maps are illustrated in Fig. 3. Figure $3 \mathrm{a}$ shows that the intrinsic model predicts negligible and low vulnerability areas to be concentrated in the center of Hamadan-Bahar aquifer. This is partly due to the deep water table in this region, which has been precipitously lowered since 1976 . In total, $54 \%$ of the area is rated as low to negligible, $27 \%$ as moderate, and $17 \%$ as high vulnerability zones based on the intrinsic model.

The specific vulnerability map in Fig. $3 b$ was constructed by combining the intrinsic vulnerability map and the potential pollution sources extracted from the landuse map. In the region, nitrate contamination of groundwater is believed to be mainly associated with intensive agricultural activities and to a lesser extent with urban landuse (Rahmani 2003; Jalali 2005; Nadafian 2007). The breakdown of the specific vulnerability regions is given in Table 5. It appears that introduction of landuse has increased the area of moderately vulnerable regions by $9 \%$.

To test the performance of the intrinsic and specific DRASTIC maps in predicting aquifer nitrate contamination, we also plotted all measured nitrate concentration in Fig. 3. As shown, the larger nitrate concentrations are more or less in the predicted high vulnerability zones, but a few wells within the low vulnerability zones also have large nitrate concentrations. While visually, there seems to be a good relationship between nitrate concentration in Hamadan-
Fig. 3 a Intrinsic vulnerability and $\mathbf{b}$ specific vulnerability maps. Also shown is the measured nitrate concentration in the wells for calibration (brown) and validation (pink) datasets. The number 65 refers to the scale of the bars a

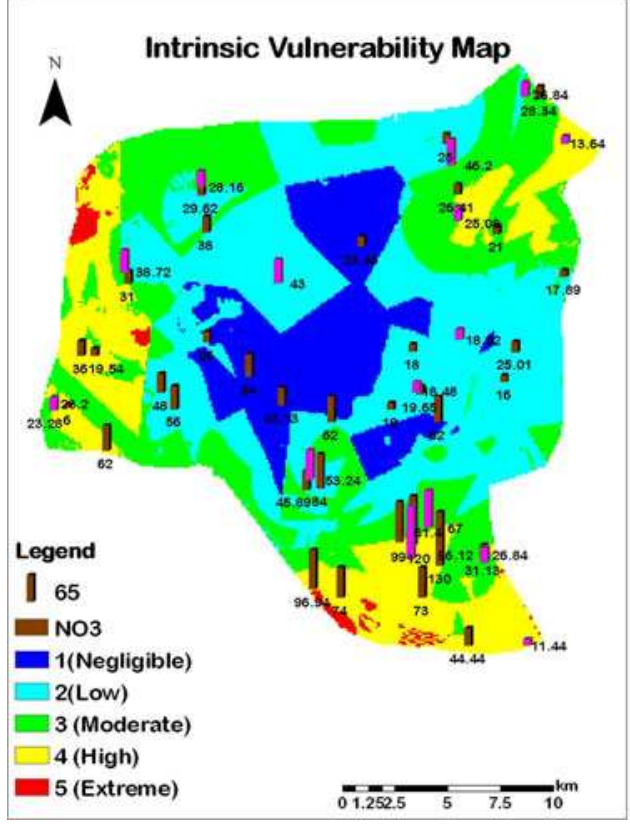

b

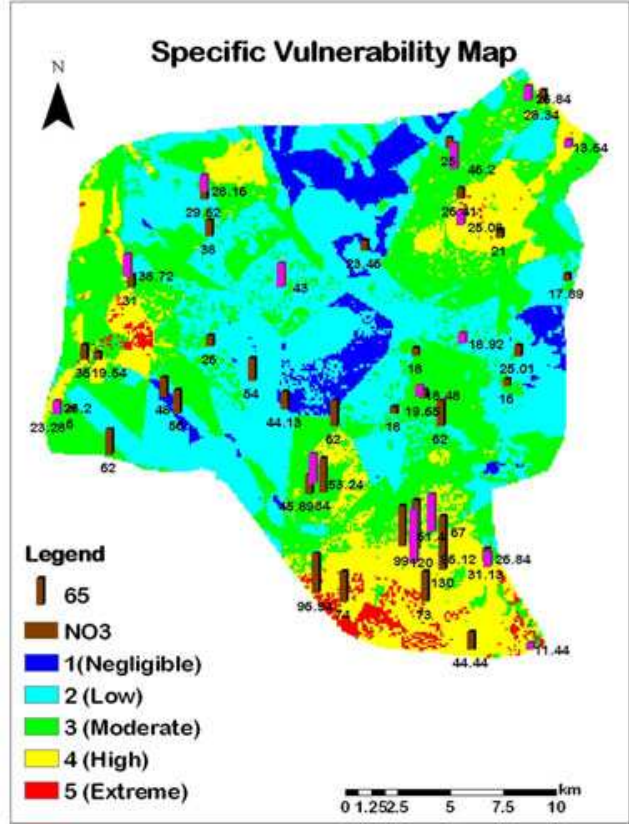


Table 6 Statistics of goodness of fit for different models

\begin{tabular}{llllr}
\hline Model & $R$-factor & $P$-factor & $R^{2}$ & MSE \\
\hline Intrinsic & - & - & 0.12 & 3,289 \\
Specific & - & - & 0.19 & 8,169 \\
Specific with optimized weights & 1.05 & 0.57 & 0.27 & 731 \\
Conditioned model rates with optimized weights & 1.19 & 0.68 & 0.52 & 570 \\
Validation data set & 1.67 & 0.67 & 0.51 & 312 \\
\hline
\end{tabular}

\begin{tabular}{lclllllll}
\hline & $\mathrm{NO}_{3}$ & $D$ & $R$ & $A$ & $S$ & $I$ & $C$ & $L$ \\
\hline $\mathrm{NO}_{3}$ & 1.0 & & & & & & \\
$D$ & $0.3(0.4)^{\mathrm{a}}$ & 1.0 & & & & & \\
$R$ & $-0.1(-0.1)$ & $0.4(0.2)$ & 1.0 & & & & \\
$A$ & $0.2(0.3)$ & $-0.3(0.2)$ & $-0.1(0.0)$ & 1.0 & & & \\
$S$ & $0.4(0.6)$ & $-0.3(0.2)$ & $-0.3(-0.2)$ & $0.3(0.4)$ & 1.0 & & \\
$I$ & $0.0(0.5)$ & $-0.3(0.3)$ & $-0.2(-0.2)$ & $0.4(0.4)$ & $0.5(0.3)$ & 1.0 & \\
$C$ & $-0.1(0.3)$ & $-0.1(0.2)$ & $-0.1(0.1)$ & $-0.1(-0.1)$ & $-0.1(0.4)$ & $0.1(0.2)$ & 1.0 & \\
$L$ & $0.3(0.4)$ & $-0.1(0)$ & $-0.4(-0.3)$ & $0.2(0.1)$ & $0.2(0.2)$ & $0.2(0.3)$ & $0.2(0.0)$ & 1.0 \\
\hline
\end{tabular}

Table 7 Correlation coefficient of measured nitrate and rates of specific and conditioned vulnerability parameters

a Numbers in brackets are correlations of the conditioned model weak as indicated in Table 7 and the near-flat slope of the trend lines. Soil, depth to water table, and landuse show the largest correlations with nitrate. Soil was also found to be important in the UK vulnerability system (Palmer and Lewis 1998). Aquifer hydraulic conductivity, recharge, and vadose zone impact exhibited the poorest correlation with nitrate as the trend lines are almost flat.

In the next step, the rates on the measured nitrate concentrations using Eq. 3 were conditioned. The revised rates are also given in Table 4 for comparison with the original DRASTIC rates. The rates are also plotted in Fig. 4 with their trend lines (blue curves). The correlations are reported in Table 7 (in brackets) as well. In general, for the conditioned rates, the correlation with nitrate has increased while the correlation between the parameters has decreased. The largest correlation now, as before, is between nitrate and soil media $(S)$ followed by vadose zone $(I)$ and landuse $(L)$. It is interesting that the correlation with $I$ changed from 0 to 0.5 after conditioning, indicating that in the study region, the class of "clay, silt with gravel" and "sand, gravel with clay and silt" play a more important role in transferring nitrate to groundwater than "clay and silt" or "clay and sand" (Table 4). Indeed in this region, "sand and gravel" were found to be less important for nitrate flow than "clay and silt" indicating the influence of macropore flow in nitrate movement as a result of cracking due to shrinkage. The recharge rate was not conditioned as recharge consisted of only two classes and was calculated based on Piscopo (2001).

After conditioning the rates, the SUFI2 program was used to optimize the parameter weights considering the 

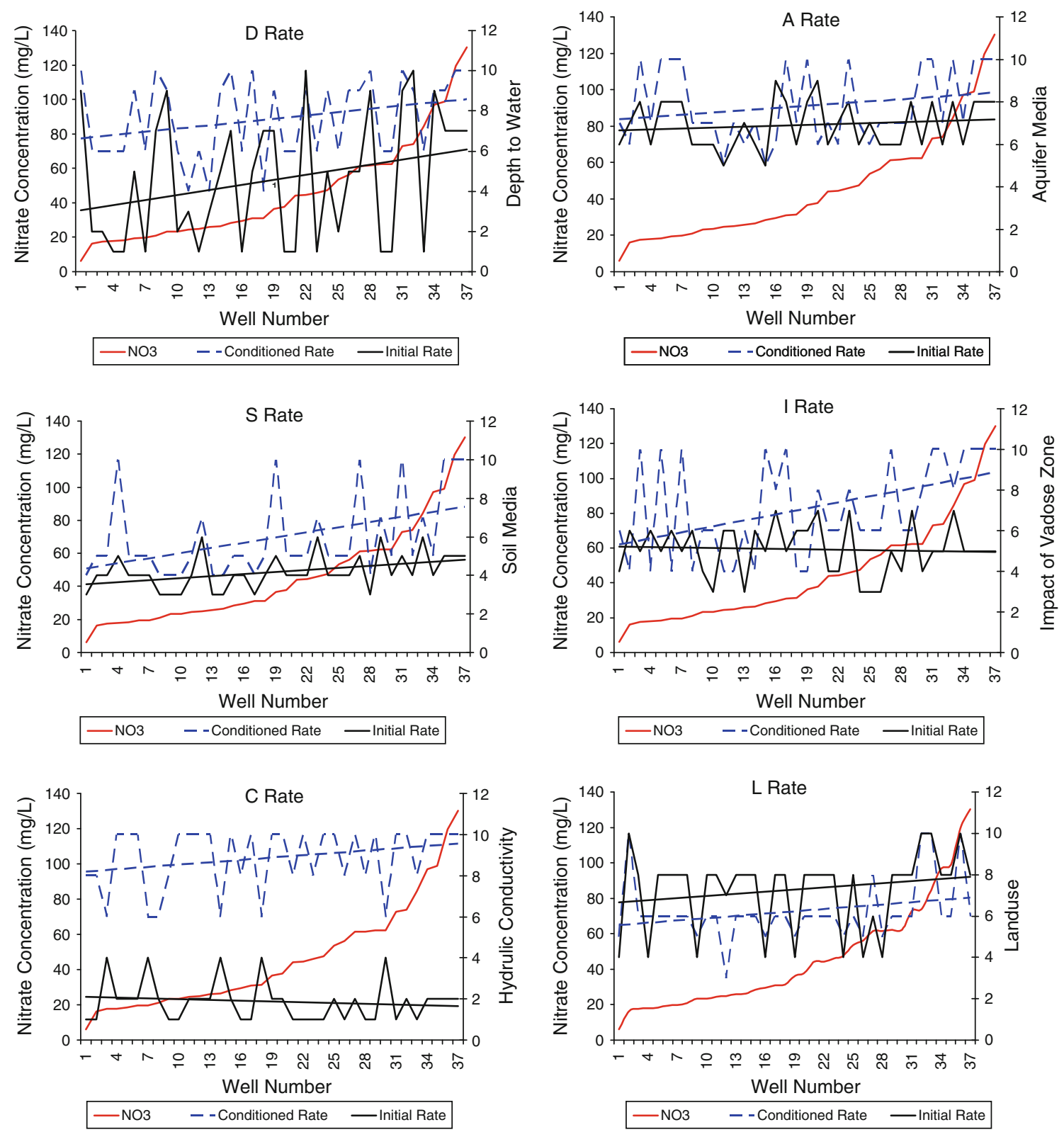

Fig. 4 Graphs showing sorted nitrate concentration and the corresponding rates for different DRASTIC parameters. Also shown is the trend line for the rates. Black curves represent the rates of the original DRASTIC model, while blue curves are the conditioned rates

objective function in Eq. 4. Table 6 shows the pertinent statistics of calibration and validation results. Ideally, the $P$-factor should approach 1 and the $R$-factor should approach zero. Validation data set has a larger $R$-factor with a similar coverage of the measured points ( $P$-factor) than the calibration data set. The MSE is, however, also quite smaller for the validation database. The $R^{2}$ values of the best simulations for validation and calibration were, 0.52 and 0.51 , respectively (Table 6).

Parameter sensitivities are determined by calculating multiple regression system in SUFI2; this provides partial information about the sensitivity of the objective function to model parameters. In the study, the objective function was found to be sensitive to soil media, impact of vadose zone, hydraulic conductivity, recharge, land use, aquifer media, and depth to water, in order of importance.

The modified vulnerability map is plotted in Fig. 5. This map provides direct nitrate concentrations instead of vulnerability index. Large nitrate concentration areas are much better depicted in this map. The Hamadan drinking water standard for nitrate is $45 \mathrm{mg}^{-1}$. According to Fig. 5, nitrate concentration below the standard was detected in $60 \%$ of the study area, while $40 \%$ have concentrations above the standard. Figure 5 shows a nitrogen 


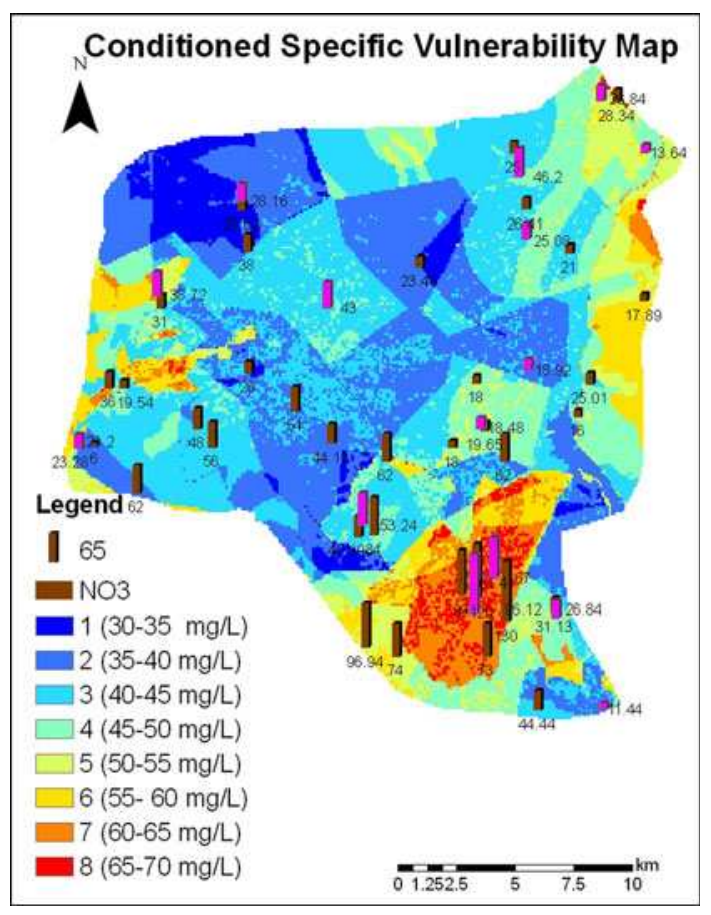

Fig. 5 The vulnerability map for the conditioned model. Also shown is the measured nitrate concentration in the wells for calibration (brown) and validation (pink) datasets

plume stretching from south to north in the eastern part of the study area following the direction of groundwater flow from the southern highlands to the flat northern regions. There appears to be another plume developing from the west toward north-east following the regional topography, which is also an indication of the groundwater flow direction. A denser set of groundwater measurement points could more clearly outline the nitrate plume stretching from south-west and western part of the region to the north and north-east.

Undoubtedly, the main source of nitrogen in the region is the $\mathrm{N}$-fertilizer and hen manure in the intensively agricultural areas. But vulnerability of the groundwater to contamination is strongly correlated to natural conditions such as soil, vadose zone, and aquifer conditions. Another important source of nitrate pollution is the sewage of Hamadan city, which is directly released into the rivers and enters the region from the south. More studies are needed to determine the share of each source in contaminating the groundwater system.

Based on the existing reports, groundwater discharges and the evolving number of wells in the region are presented in Table 8. Figure 6 shows the water table status in 1976 and the one averaged over a 6-year period in 2001-2006. There has been a tremendous rise in the number of wells withdrawing water from the aquifers and a drastic drop in the water table in the central plain of Hamadan-Bahar. This has undoubtedly created a complex regional flow system. The DRASTIC models show small vulnerability in the central plain mainly because the groundwater table is quite deep. But in reality, the vulnerability of this region should be quite large because groundwater gradient should now be directed towards the central valley bringing in polluted water from all sides. More groundwater samples in the central plain may, therefore, reveal a different contamination picture.

For a comparison with the present condition, in Fig. 7 the intrinsic vulnerability map of 1976 was plotted. All DRASTIC parameters between the past and the present should have remained fairly constant, except for the depth to water table. The greatest change between the two periods is in the central part of the plain, spatially from southwest to north-east. The water table in the central region was quite high in 1976; hence DRASTIC calculates a larger vulnerability. In 1976, about $39 \%$ of the region was predicted to have a high intrinsic vulnerability, while the current prediction puts this number at around $17 \%$. This reduction is entirely due to declining water table in the central valley. But in reality, macropore flow can more than compensate for the lowering of water table in delivering contaminants to groundwater.

As groundwater table is higher in the regions surrounding the valley than in the middle of the HamadanBahar plain, a reversal of flow gradient towards the center is expected, which will bring in polluted groundwater from the north, south, and west. The central valley is, hence, a danger zone, which needs to be carefully monitored.

Table 8 Temporal changes in the number of wells and groundwater discharge in Hamadan-Bahar aquifer

\begin{tabular}{|c|c|c|c|c|c|c|c|c|c|}
\hline \multirow[t]{2}{*}{ Year } & \multicolumn{2}{|c|}{ Deep wells } & \multicolumn{2}{|c|}{ Semi-deep wells } & \multicolumn{2}{|l|}{ Qanats } & \multicolumn{2}{|l|}{ Springs } & \multirow{2}{*}{$\begin{array}{l}\text { Total discharge } \\
(\mathrm{MCM})\end{array}$} \\
\hline & Number & $\begin{array}{l}\text { Discharge } \\
\text { (MCM) }\end{array}$ & Number & $\begin{array}{l}\text { Discharge } \\
\text { (MCM) }\end{array}$ & Number & $\begin{array}{l}\text { Discharge } \\
\text { (MCM) }\end{array}$ & Number & $\begin{array}{l}\text { Discharge } \\
\text { (MCM) }\end{array}$ & \\
\hline 1976 & 9 & 4 & 692 & 97 & 43 & 29 & - & - & 130 \\
\hline 1991 & 991 & 248 & 1,287 & 66 & 107 & 19 & 121 & 13 & 346 \\
\hline 2003 & 1,024 & 228 & 1,250 & 71 & 111 & 31 & 327 & 8 & 339 \\
\hline
\end{tabular}

MCM million cubic meters 
Fig. 6 The map of depth to groundwater table in a 1976 and b averaged over 2001-2006

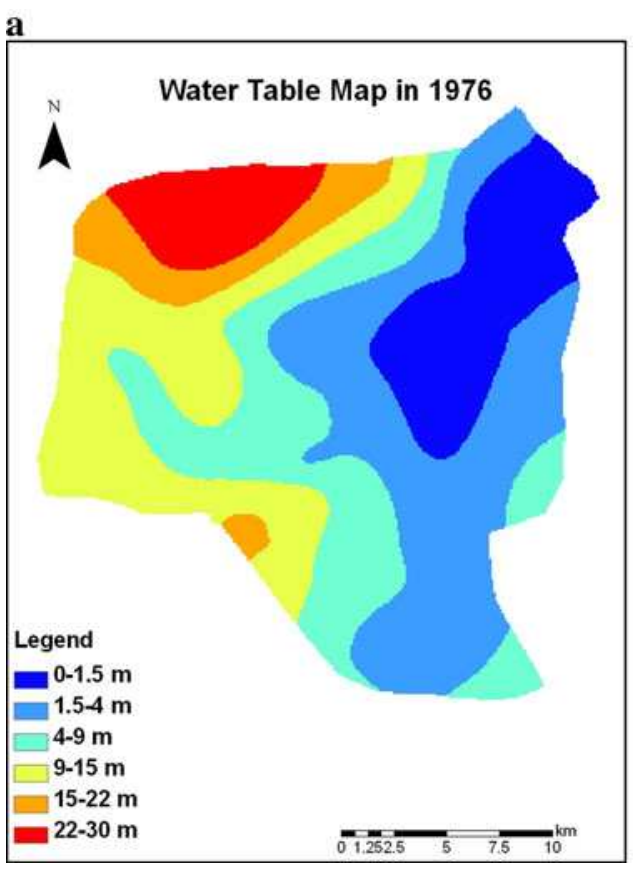

b

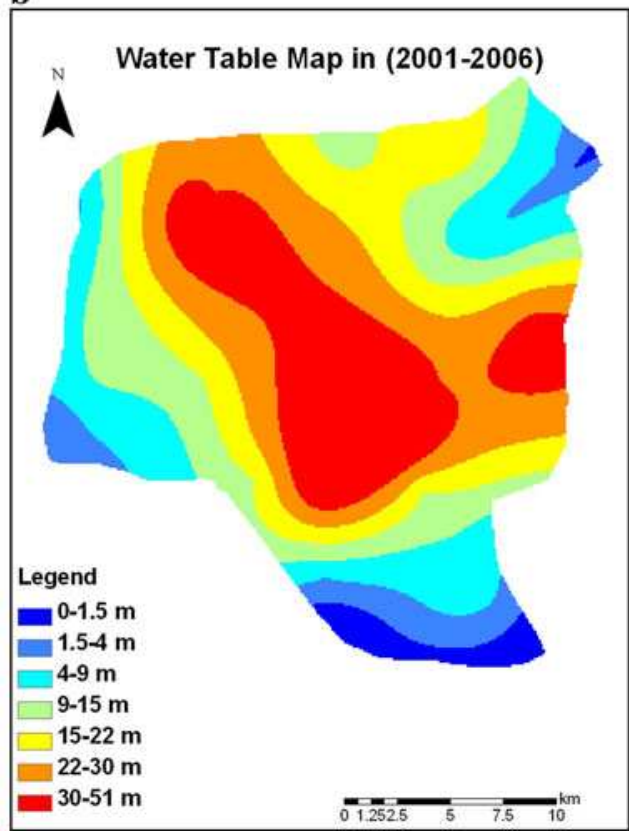

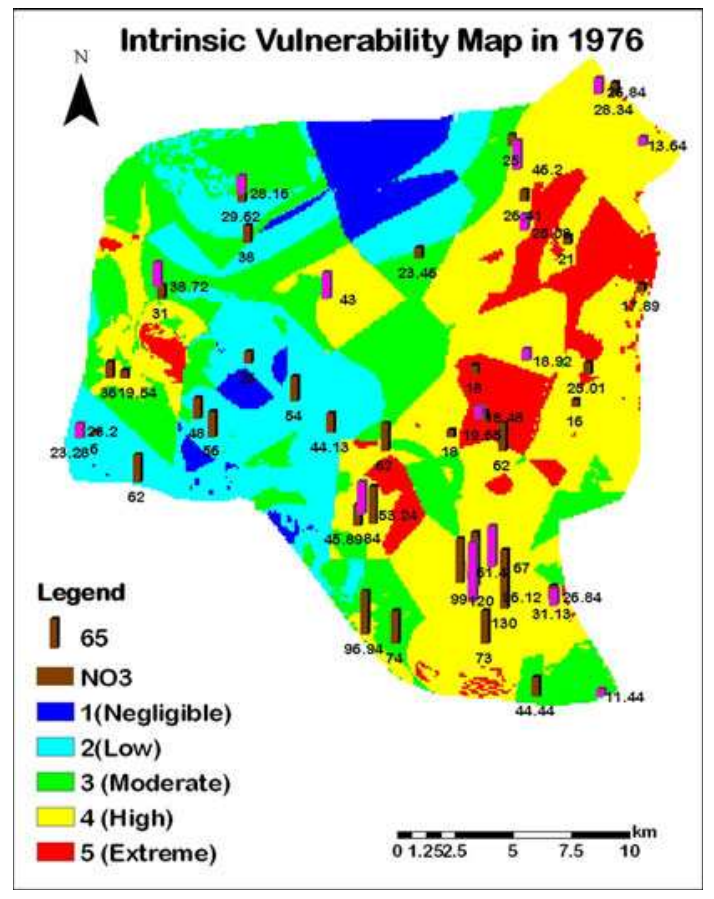

Fig. 7 DRASTIC vulnerability map based on the 1976 groundwater depth data

\section{Conclusions}

This study confirmed that training of DRASTIC model rates based on measured nitrate concentrations significantly improves model's ability to delineate vulnerable sites. Although the number of measured data in the calibration data set was small, but the favorable results of the independent validation dataset did not show severe over fitting of the parameters. In a following study, we will consider modeling the region with SWAT (Arnold et al. 1998) hydrologic simulator and implementation of alternative BMPs to alleviate the aquifer nitrate problems.

Acknowledgments The authors wish to acknowledge Hamadan Regional Water Authority, Water and Wastewater Co. of Hamadan, Isfahan University of Technology, and the Swiss Federal Institute for Aquatic science and Technology, Eawag, for providing assistance to conduct this study.

\section{References}

Abbaspour KC (2007) User manual for SWAT-CUP, SWAT calibration and uncertainty analysis programs. Swiss Federal Institute of Aquatic Science and Technology, Eawag, Dübendorf, Switzerland. http://www.eawag.ch/organisation/ abteilungen/siam/software/swat/index_EN. Accessed Aug 2009

Abbaspour KC, Yang J, Maximov I, Siber R, Bogner K, Mieleitner J, Zobrist J, Srinivasan R (2007) Modelling hydrology and water quality in the pre alpine/alpine Thur watershed using SWAT. J Hydrol 333:413-430

Al-Adamat RAN, Foster IDL, Baban SMJ (2003) Groundwater vulnerability and risk mapping for the Basaltic aquifer of the Azraq basin of Jordan using GIS, remote sensing and DRASTIC. Appl Geogr 23:303-324

Aller L, Bennett T, Lehr JH, Petty RJ, Hackett G (1987) DRASTIC: a standardized system for evaluating ground water pollution potential using hydrogeologic settings. EPA-600/2-87-035, EPA, Washington

Almasri MN (2008) Assessment of intrinsic vulnerability to contamination for Gaza coastal aquifer, Palestine. J Environ Manage 88(4):577-593

Arnold JG, Srinivasan R, Muttiah RS, Williams JR (1998) Large area hydrologic modeling and assessment-Part 1: model development. J Am Water Resour Assoc 34:73-89 
Babiker IS, Mohamed AAM, Hiyama T, Kato K (2005) A GIS based DRASTIC model for assessing aquifer vulnerability in Kakamigahara Heights, Gifu Prefecture, Central Japan. Sci Total Environ 345(1-3): 127-140

Chitsazan M, Akhtari Y (2008) A GIS-based DRASTIC model for assessing aquifer vulnerability in Kherran plain, Khuzestan, Iran. Water Resour Manage. doi:10.1007/s11269-008-9319-8

Garrett P, Williams JS, Rossoll CF, Tolman AL (1989) Are ground water vulnerability classification systems workable? In: Proceedings of FOCUS conference on eastern regional ground water issues, Kitchener, Ontario, Canada, National Water Well Association, Dublin, Ohio, 17-19 October, pp 329-343

Gogu RC, Dassargues A (2000) Current trends and future challenges in groundwater vulnerability assessment using overlay and index methods. Environ Geol Environ Geol 39(6):549-559

Hamza MH, Added A, Rodriguez R, Abdeljaoueda S, Ben Mammou A (2007) A GIS-based DRASTIC vulnerability and net recharge reassessment in an aquifer of a semi-arid region (Metline-Ras Jebel-Raf Raf aquifer, Northern Tunisia). J Environ Manage $84: 12-19$

Jalali M (2005) Nitrates leaching from agricultural land in Hamadan, western Iran. Agric Ecosyst Environ 110:210-218

Kalinski RJ, Kelly WE, Bogardi I, Ehrman RL, Yamamoto PO (1994) Correlation between DRASTIC vulnerabilities and incidents of VOC contamination of municipal wells in Nebraska. Ground Water 32(1):31-34

McKay MD, Beckman RJ, Conover WJ (1979) A comparison of three methods for selecting values of input variables in the analysis of output from a computer code. Technometrics 21:239-245

McLay CDA, Dragden R, Sparling G, Selvarajah N (2001) Predicting groundwater nitrate concentrations in a region of mixed agricultural land use: a comparison of three approaches. Environ Pollut 115:191-204

Merchant J (1994) GIS-based groundwater pollution hazard assessment: a critical review of the DRASTIC model. Photogramm Eng Remote Sens 60(9):1117-1127

Mohammadi K, Niknam R, Majd VJ (2008) Aquifer vulnerability assessment using GIS and fuzzy system: a case study in TehranKaraj aquifer, Iran. Environ Geol. doi:10.1007/s00254-008-1514-7

Moradi A, Abbaspour KC, Afyuni M (2005) Modelling field-scale cadmium transport below the root zone of a sewage sludge amended soil in an arid region in Central Iran. J Contam Hydrol 79(3-4):187-206

Nadafian H (2007) Simulation of groundwater pollution around drinking water wells in Hamadan city. M.Sc. dissertation, Shahid Beheshti University, Tehran, Iran

Palmer RC, Lewis MA (1998) Assessment of groundwater vulnerability in England and Wales. In: Robins NS (ed) Groundwater pollution, aquifer recharge and vulnerability, special publications vol 130. Geological Society, London, pp 191-198

Panagopoulos GP, Antonakos AK, Lambrakis NJ (2006) Optimization of DRASTIC model for groundwater vulnerability assessment, by the use of simple statistical methods and GIS. Hydrogeol J 14:894-911

Piscopo G (2001) In: Groundwater vulnerability map, explanatory notes, Castlereagh Catchment, NSW. Department of Land and Water Conservation, Australia. http://www.dwe.nsw.gov.au/water/pdf/ quality_groundwater_castlereagh_map_notes.pdf. Accessed Aug 2008

Rahman A (2008) A GIS-based DRASTIC model for assessing groundwater vulnerability in shallow aquifer in Aligarh, India. Appl Geogr 28:32-53

Rahmani A (2003) Study and investigation of pollution in groundwater of Hamadan-Bahar plain. Environmental Organization of Hamadan, Iran

Rosen L (1994) A study of the DRASTIC methodology with emphasis on Swedish conditions. Ground Water 32:278-285

Secunda S, Collin M, Melloul AJ (1998) Groundwater vulnerability assessment using a composite model combining DRASTIC with extensive land use in Israel's Sharon region. J Environ Manage 54:39-57

Tyner JS, Wright WC, Yoder RE (2007) Identifying long-term preferential and matrix flow recharge at the field scale. T ASABE 50(6):2001-2006

Villeneuve JP, Banton O, Lafrance P (1990) A probabilistic approach for the groundwater vulnerability to contamination by pesticides: the VULPEST model. Ecol Model 51:47-58

Vrba J, Zaporozec A (1994) Guidebook on mapping groundwater vulnerability, vol 16. International Association of Hydrogeologists, Heise 